\title{
Condiçōes de Trabalho \\ e Riscos no Trânsito Urbano na Ótica de Trabalhadores Motociclistas
}

I ${ }^{1}$ Daniela Wosiack da Silva, ${ }^{2}$ Selma Maffei de Andrade, ${ }^{3}$ Darli Antonio Soares, ${ }^{4}$ Elisabete de Fátima P. de Almeida Nunes, ${ }^{5}$ Regina Melchior I

Resumo: Uma das profissōes que mais se expandem no Brasil é a dos motociclistas profissionais, o que pode aumentar os acidentes de trânsito envolvendo esta categoria. Este estudo tem como objetivo identificar e analisar qualitativamente a percepção de motoboys acerca de aspectos relacionados ao seu trabalho, aos riscos no trânsito e à ocorrência de acidentes. Os dados foram coletados por meio de grupo focal, realizado em fevereiro de 2005, com 11 motoboys atuantes em Londrina (PR). Este artigo focaliza os principais motivos que levaram os motoboys à inserção na profissão, suas condições de trabalho, os riscos a que estão expostos e seu envolvimento em acidentes de trânsito. Os principais motivos para a inserção na profissão foram o desemprego e a baixa escolaridade. A pressão exercida pelas empresas e clientes por entregas rápidas é fator determinante para a adoção de comportamento de risco no trânsito, tendo o ganho por produtividade menor peso na tomada de decisões. Todos os participantes do estudo relataram envolvimento em acidentes de trânsito. Melhorar suas condições de trabalho é o grande desafio colocado no momento, tanto para os próprios motoboys, por meio da união da categoria e luta por seus direitos, como para a sociedade em geral, cabendo ao Estado fiscalizar as empresas que oferecem serviços de entrega e estabelecer normas que aumentem a segurança desses motociclistas no desempenho do seu trabalho.

> Palavras-chave: Acidentes de trânsito; motocicletas; condições de trabalho; comportamento de risco; risco ocupacional.

\author{
1 Mestre em Saúde Coletiva, \\ professora no Departamento de \\ Fisioterapia da Universidade \\ Estadual de Londrina. \\ Endereço eletrônico: \\ daniwosiack@hotmail.com. \\ 2 Doutora em Saúde Pública, \\ professora associada no \\ Departamento de Saúde \\ Coletiva da Universidade \\ Estadual de Londrina. \\ Endereço eletrônico: \\ semaffei@sercomtel.com.br. \\ ${ }^{3}$ Doutor em Medicina, \\ professor associado no \\ Departamento de Saúde \\ Coletiva da Universidade \\ Estadual de Londrina. \\ Endereço eletrônico: \\ soaresda@sercomtel.com.br. \\ ${ }^{4}$ Doutora em Saúde Coletiva, \\ professora adjunta no \\ Departamento de Saúde \\ Coletiva da Universidade \\ Estadual de Londrina. \\ Endereço eletrônico: \\ alnunes@sercomtel.com.br. \\ ${ }^{5}$ Doutora em Saúde Pública, \\ professora adjunta no \\ Departamento de Saúde \\ Coletiva da Universidade \\ Estadual de Londrina. \\ Endereço eletrônico: \\ reginamelchior@uel.br.
} Aprovado em: 10/12/2007. 


\section{Introdução}

As profundas modificações sofridas pelo mundo do trabalho a partir dos anos 1980 são chamadas de acumulação flexível, padrão produtivo caracterizado pela flexibilização e precarização nos processos de trabalho, entre outros. Essa acumulação se caracteriza também pelo surgimento de novos setores de produção, formas de fornecimento de serviços financeiros e mercados e, ainda, pelo aumento expressivo de empregos no chamado "setor de serviços" (ABRAMIDES; CABRAL, 2003). No setor brasileiro de serviços, uma das profissōes que mais tem se ampliado é a dos motociclistas profissionais (conhecidos como motoboys ou mototaxistas). Os acidentes de trânsito envolvendo essa categoria profissional tendem, portanto, a aumentar no país (IPEA, 2003).

Barros et al. (2003), em Pelotas-RS, apontam um envolvimento desproporcionalmente alto de motocicletas em acidentes de trânsito em relação ao tamanho da frota, além de elevada taxa de letalidade entre acidentados ocupantes desse veículo. Segundo os autores, os motociclistas daquela cidade são constituídos principalmente por homens jovens desempregados que, em diversos casos, atuam como motoboys ou mototaxistas, como forma de obter alguma renda.

Em Londrina, cidade de médio porte do Estado do Paraná, com cerca de 500 mil habitantes, os motociclistas estão entre as principais vítimas do trânsito (ANDRADE; MELLO JORGE, 2000; BASTOS; ANDRADE; SOARES, 2005). Os motoboys encontram-se mais susceptíveis a sofrerem acidentes, tanto por sua maior exposição nas vias públicas, quanto pela necessidade de realizarem o maior número possível de entregas em um curto intervalo de tempo, levando esta população à adoção de altas velocidades e de manobras arriscadas no trânsito (ANDRADE; MELLO JORGE, 2000; DINIZ, 2003).

Apesar da importância do tema, tanto pela crescente utilização dos serviços de entrega quanto pela gravidade e grande número de vítimas resultantes de acidentes envolvendo motociclistas profissionais, há raras publicações sobre o tema, destacando-se, no país, as de Diniz (2003) e Diniz, Assunção e Lima (2005a; 2005b) e de Veronese (2004) e Veronese e Oliveira (2006). Os riscos a que estão expostos esses trabalhadores, portanto, compõem um novo campo de estudo, ainda pouco explorado.

O conceito de risco é relativamente recente na sociedade contemporânea e, apesar de seu caráter polissêmico, no contexto da Epidemiologia, "a bibliografia 
existente [...] aponta para sua estreita associação com 'o ato ou efeito de um sucesso incerto e potencialmente indesejável'.” (AYRES, 1997, p. 203). Para outros autores (ALMEIDA FILHO; COUTINHO, 2007), são identificados três pressupostos filosóficos nas formas de apresentação do conceito de risco: risco como perigo, no discurso social comum; risco individual, dominante na Clínica; risco populacional, como conceito da Epidemiologia; e risco estrutural, para a Saúde Ambiental/ Ocupacional. Esses pesquisadores, ainda, argumentam que há necessidade de incorporar o conceito de "risco contingencial" no campo de práticas da Saúde Coletiva, entendendo-se por "contingentes" que "os processos sociais são corporais, históricos, complexos, fragmentados, conflitivos, dependentes e incertos" (ALMEIDA FILHO; COUTINHO, 2007, p. 109).

O risco, como conceito fundamental da Epidemiologia, é uma "entidade probabilística", fazendo com que as previsóes sobre os agravos sejam incertas e discutíveis, pois sempre "há a possibilidade de ocorrerem imponderabilidades incontroláveis" (CASTIEL, 1996, p. 239). Esse mesmo autor segue o raciocínio feito por Almeida Filho e Coutinho (2007), ao destacar que uma das principais críticas ao enfoque quantitativista do risco epidemiológico seria por este constituir "uma entidade, que possuiria uma 'existência' autônoma, objetivável, independente dos complexos contextos socioculturais nos quais as pessoas se encontram" (CASTIEL, 1996, p. 243). Nesse contexto, Spink (2001) destaca, nas abordagens iniciais sobre risco, a desvalorização dos valores que permeiam a percepção do público sobre esse conceito. Essa autora aponta, ainda, uma dimensão positiva do risco na perspectiva da sociedade contemporânea, na qual se destaca o risco-aventura, que se manifesta, por exemplo, nas práticas dos esportes radicais e nas profissões tradicionais que envolvem perigo (bombeiros, detetives, etc.) ou que emergem em conseqüência dos riscos produzidos pela sociedade e tecnologias atuais (gerentes de investimentos de risco em bancos, responsáveis pela segurança de tecnologias, entre outras).

Por outro lado, a mídia tem papel crucial na linguagem corrente sobre risco. Em análise de matérias publicadas em um jornal de grande circulação, identificouse diversidade na linguagem sobre riscos: de um lado, uma linguagem formal, isto é, risco como fatores e probabilidades de risco; de outro, como sinônimo de perigos variados (SPINK; MEDRADO; MELLO, 2002). Nesse mesmo trabalho, os autores destacam a negatividade contida nos sentidos de risco (453 matérias com conotação negativa e apenas uma considerando a positividade do risco), embora reconheçam 
a existência de um movimento contra-hegemônico no sentido de entender o risco como "oportunidade de expressão, e de ampliação de perspectivas" (SPINK; MEDRADO; MELLO, 2002, p. 162).

Riscos para acidentes de trânsito, no sentido formal do conceito, já foram bem estabelecidos na literatura sobre o tema, e a Organização Mundial da Saúde os sintetiza em: a) riscos que influenciam a exposição, tais como os fatores socioeconômicos; b) riscos de envolvimento em acidentes (como defeitos nas pistas, abuso de velocidade); c) riscos que influenciam a gravidade do acidente (equipamentos de proteção inadequados ou não usados, velocidade, por exemplo); d) riscos que influenciam a gravidade do trauma na fase pósacidente (como retardo no resgate das vítimas, falta de atendimento médico/ hospitalar adequado) (WHO, 2004).

Entendendo que risco tem múltiplas acepções e que os riscos de acidentes de trânsito, no seu sentido formal (WHO, 2004), podem ser compreendidos de forma diversa pelo público (SILVA; ALVARENGA; AYRES, 2006), o presente estudo teve como objetivo identificar e analisar a percepção de motoboys quanto a aspectos relacionados ao seu processo laboral, aos riscos no trânsito e à ocorrência de acidentes no município de Londrina (PR). Entende-se por percepção de risco, neste estudo, a maneira como os sujeitos pesquisados compreendem, reinterpretam e concebem os riscos no trânsito, no quadro de referências culturais e sociais de seu grupo (PAULILO; JEOLÁS, 2005; SILVA; ALVARENGA; AYRES, 2006).

Esta pesquisa faz parte do estudo "Acidentes e violências no Paraná: magnitude, tendência, fatores associados, seqüelas e gastos hospitalares", aprovado pelo Comitê de Ética em Pesquisa da Universidade Estadual de Londrina (Parecer n. 287/04).

\section{Metodologia}

A abordagem adotada foi qualitativa, utilizando-se a técnica de grupo focal. Segundo Debus (1988), esta é uma técnica de investigação por meio da qual se torna possível uma aproximação rápida com os pensamentos e opiniōes de um determinado grupo de pessoas, com características homogêneas, sobre o assunto que se pretende investigar. De acordo com Carlini-Cotrim (1996), esta técnica permite que os participantes falem livre e espontaneamente sobre o tema que está sendo objeto da pesquisa.

A utilização do grupo focal é recomendada por oferecer maior possibilidade de refletir coletivamente sobre uma temática que faz parte da vida das pessoas reunidas. 
Pressupondo que percepções, atitudes, opiniōes e representações são socialmente construídas, a expressão dos sujeitos envolvidos seria mais facilmente captada durante um processo de interação em que a fala de uns pode fazer surgir opiniōes de outros. Pela observação dos grupos focais, é possível, ainda, conhecer o modo como as pessoas avaliam ou definem uma experiência, idéia ou evento. Os processos de interação entre os participantes são reproduçóes do que ocorre fora dos grupos e geram resultados e aproximações do problema que está em estudo (WESTPHAL; BÓGUS; FARIA, 1996).

Esse grupo focal teve caráter exploratório e seu objetivo foi levantar questóes referentes ao universo do cotidiano dos motoboys. Os resultados obtidos subsidiaram o desenvolvimento de um questionário fechado, com a finalidade de ser aplicado a um grupo maior de motoboys e, assim, também obter evidências de caráter quantitativo sobre o tema.

O grupo de motoboys que participou da pesquisa foi selecionado de forma intencional, após levantamento por meio de observação nas principais vias públicas do município de Londrina, por um período de dois meses (setembro e outubro de 2004), visando a identificar, nas caixas das motocicletas de motoboys, os principais tipos de empresas que utilizavam seus serviços, sendo identificados os seguintes sete principais tipos: restaurantes/lanchonetes/pizzarias, farmácias/drogarias, empresas de entregas gerais (entregas terceirizadas), de entrega de água mineral, lojas de tintas, de botijōes de gás comum e papelarias/copiadoras.

Para a presente investigação, procurou-se contemplar os diferentes tipos de empresa de atuação dos motoboys, sendo selecionados 11: três atuantes em restaurantes; dois em farmácias e drogarias; um funcionário de empresa de entregas gerais (entregas terceirizadas); um funcionário de loja de tintas; um de empresa copiadora; um que trabalhava com entrega de galóes de água mineral e um que entregava botijōes de gás. Além desses, também foi incluído um trabalhador considerado "autônomo", sem atuação predominante em quaisquer dessas empresas.

Foi utilizado um roteiro semi-estruturado para organização da discussão, que contemplou os seguintes aspectos: a) motivos para inserção na profissão; b) vantagens e desvantagens inerentes à profissão; c) principais motivos que levam à ocorrência de acidentes envolvendo motoboys; d) percepçôes a respeito de seu próprio comportamento no trânsito e de outros usuários da via pública (motoristas de carro, pedestres e ciclistas) em relação aos motoboys. 
Os dados foram coletados durante um grupo focal realizado em fevereiro de 2005. A discussão durou uma hora e vinte minutos e foi gravada em áudio e vídeo, sendo posteriormente transcrita. Os motoboys foram previamente informados sobre os objetivos da pesquisa e assinaram termo de consentimento livre e esclarecido autorizando a gravação, filmagem e utilização dos dados para a pesquisa.

Após a introdução do primeiro tema, houve poucas intervençôes do moderador, que ocorreu apenas para inserir questões que não surgiram naturalmente na conversa dos participantes, para obter esclarecimento sobre algum assunto ou estimular alguma discussão.

Após a transcrição das falas, foram realizadas várias leituras, com o objetivo de se encontrar as unidades de significados, utilizando a técnica de análise de conteúdo - definida por Bardin (1977) como um conjunto de técnicas de análise da comunicação, visando a obter, por meio de procedimentos sistemáticos e objetivos de descrição dos conteúdos das mensagens, indicadores, quer quantitativos, quer qualitativos, que propiciem a inferência relativa às condições de produção e de recepção dessas mensagens. Este tipo de análise tem como procedimento tratar informações, atitudes ou temas contidos em uma mensagem ou documento. Neste estudo, foi usada a técnica de análise de conteúdo temática, sendo observadas as etapas preconizadas: pré-análise, análise do material, tratamento dos resultados, inferência e interpretação.

A partir da análise do material obtido, foram definidas as seguintes categorias: a) Inserção na profissão, b) Condições de trabalho e c) Riscos e acidentes.

\section{Resultados e discussão}

Os onze participantes do grupo focal eram todos do sexo masculino e com média de idade de 26 anos. Foi encontrada média de 9,4 anos de estudo, sendo que, destes, um não concluíra sequer os quatro primeiros anos do ensino fundamental. O tempo de atuação como motoboy variou de seis meses a 11 anos, sendo que oito tinham tempo de atuação entre um a cinco anos (quadro 1). 
Quadro 1: Caracterização dos motoboys participantes de grupo focal.

Londrina, 2005

\begin{tabular}{|l|c|c|c|}
\hline \multicolumn{1}{|c|}{ Motoboys } & Idade (anos) & $\begin{array}{c}\text { Escolaridade } \\
\text { (anos) }\end{array}$ & $\begin{array}{c}\text { Tempo de atuação } \\
\text { como motoboy }\end{array}$ \\
\hline M1 - Restaurante & 40 & 10 & 2 anos e 6 meses \\
\hline M2 - Restaurante & 19 & 11 & 6 meses \\
\hline M3 - Restaurante & 22 & 8 & 2 anos \\
\hline M4 - Farmácia & 21 & 10 & 3 anos \\
\hline M5 - Farmácia & 35 & 11 & 9 anos \\
\hline M6 - Entregas Gerais & 20 & 11 & 5 anos \\
\hline M7 - Loja de tintas & 24 & 10 & 5 anos \\
\hline M8 - Papelaria/Copiadoras & 28 & 7 & 11 anos \\
\hline M9 - Entrega de galões de água mineral & 23 & 11 & 2 anos \\
\hline M10 - Entrega de botijões de gás & 21 & 3 & 1 ano \\
\hline M11- Autônomo & 33 & 11 & 1 ano e 8 meses \\
\hline
\end{tabular}

São apresentados, a seguir, os principais temas abordados pelos motoboys durante a discussão no grupo focal segundo as categorias de análise (Quadro 2).

Quadro 2: Principais temas abordados em grupo focal realizado com motoboys segundo as categorias de análise. Londrina, 2005

\begin{tabular}{|l|l|}
\hline Categorias de análise & Temas \\
\hline a) Inserção na profissão & - Desemprego \\
& - Forma de melhorar a renda \\
& - Baixa escolaridade \\
\hline b) Condições de trabalho & - Trabalho informal \\
(Vínculo funcional, & - Sensação de liberdade e autonomia \\
Condiçöes favoráveis e & - Oportunidade de conhecer novos lugares e fazer novas amizades \\
trabalho e comportamento & - Boa remuneração \\
no trânsito) & - Exposição ao sol e à chuva \\
& - Desgaste físico e emocional \\
& - Medo de assaltos \\
& - Dificuldades no trânsito \\
& - Pressão patronal por entregas rápidas e ganho por produtividade \\
& - Elevada densidade de trabalho e alternância de turnos \\
& - Adoção de estratégias para reduzir percurso e andar mais rápido \\
\hline & - Envolvimento freqüente em acidentes de trânsito \\
& - Reconhecimento da imprudência no trânsito \\
& - Conflitos com demais motoristas e discriminação da sociedade \\
\hline c) Riscos e acidentes & - Violência urbana \\
& \\
\hline
\end{tabular}




\section{Inserção na profissão}

Ao serem indagados sobre o que os levou à profissão, os motoboys deste estudo apontaram o desemprego como fator determinante para o ingresso neste tipo de trabalho, e como forma de melhorar a renda, como ilustram os depoimentos: "Nem todos que trabalham com moto [...] trabalham porque gostam. A maioria é por necessidade, porque nós não temos outra renda, outra forma de trabalho" (M11). "Porque a gente procura, procura, procura um emprego e não acha, e então vai pro motoboy; não tem jeito, a gente tem contas [para pagar]" (M9). "Para melhorar a renda, para fazer dois serviços, pegar um bico com a moto [...]" (M1).

Se não se pode desconsiderar a reflexão de Spink (2001) sobre risco-aventura, definido como disposição em correr riscos, como possível motivação para os motoboys se inserirem em uma profissão em que velocidade e coragem são características altamente valorizadas, a presente investigação revela que a profissão motoboy surge como uma solução para resolver o problema do desemprego, na falta de melhores opções de trabalho, e não como uma opção por uma profissão que traz emoçôes, como destacam outros estudos (VERONESE, 2004; DINIZ; ASSUNÇÃO; LIMA, 2005a).

Segundo Oliveira e Mendes (1997) houve, no Brasil, um aumento gradativo do número de pessoas que buscam garantir sua subsistência e de seus familiares em ocupações pouco estáveis, no mercado informal de trabalho. Assim, o aumento do uso da motocicleta como instrumento de trabalho pode ser explicado, provavelmente, pelo desemprego entre jovens observado no Brasil na última década. Nesse período, com a estabilização da inflação e queda do nível de atividade econômica, houve aumento da taxa de desemprego, especialmente entre os trabalhadores mais jovens (REIS; CAMARGO, 2005). Ainda na década de 1990, as mudanças econômicas ocorridas com o controle da inflação, com a abertura comercial, com as privatizaçóes e as inovações tecnológicas contribuíram para a elevação do desemprego, da informalidade e da flexibilização das relações de trabalho. Observaram-se redução de postos de trabalho no setor industrial e aumento do emprego no setor de serviços, além do aumento da terceirização de mão-de-obra em busca de relações menos rígidas de trabalho que permitissem, às empresas, redução de seus custos (CHAHAD, 2003; WÜNSCH FILHO, 1999).

A baixa escolaridade também foi identificada, pelos motoboys do estudo, como motivo para inserção na profissão, indicando despreparo para o exercício de outras 
funções que exijam maior qualificação. Segundo Chahad (2003), devido à inserção de novas tecnologias, as empresas exigem maior capacitação dos trabalhadores. Assim, trabalhadores com pouca escolaridade e baixa qualificação vão sendo gradativamente excluídos do mercado formal de trabalho. Dessa forma, o trabalho informal, que inicialmente era um "bico", passa a ser uma situação permanente, como pode se observar em relação ao tempo de atuação dos motoboys do presente estudo (quadro 1).

\section{Condições de trabalho}

\section{Vínculo funcional}

Foi abordada, durante a discussão, a diferença entre o serviço do motoboy autônomo e o do funcionário contratado por empresa. Enquanto o motoboy autônomo tem maior liberdade, o vinculado a uma firma tem que obedecer aos horários ditados pela empresa. Nota-se maior satisfação com o processo de trabalho no discurso do trabalhador autônomo: "Você é um pouco mais dono de si, porque você é autônomo, você tem um pouco de liberdade" (M8).

No entanto, mesmo no caso de funcionários de empresa, o trabalhador tem uma sensação de maior autonomia em relação à execução de suas tarefas quando comparado a outros tipos de trabalho, talvez devido ao fato de o exercício profissional ocorrer na maior parte do tempo longe do olhar do chefe, como reflete a fala de um dos motoboys: "Você não tem que estar confinado em uma sala, junto com patrão, é uma liberdade a mais [...]" (M9).

O vínculo informal de trabalho é uma característica da profissão. Dos 11 participantes do estudo, apenas um tinha registro em carteira de trabalho. Devido à forma de organização do trabalho vigente, foram relatados a falta de assistência e o não-recebimento de qualquer benefício em caso de acidente: "Eu fazia um bico para eles e me mandaram embora, [...] e como eu não era registrado nessa firma fiquei com o prejuízo" (M8).

Nesse contexto, direitos garantidos pela legislação trabalhista aos trabalhadores com registro em carteira, como férias, décimo-terceiro salário, aposentadoria, segurodesemprego e licença por doença, são sistematicamente negados a esses trabalhadores. Precárias condições de trabalho são observadas, em geral, entre trabalhadores de categorias profissionais não-regulamentadas ou pouco organizadas, como é o caso dos motoboys. A falta de regulamentação profissional, aliada à grande oferta de mão-de-obra, contribui para a manutenção das más condições de trabalho 
a que os motoboys são submetidos, situação que os expõe ao desgaste no trabalho e eleva sobremaneira o risco de se envolverem em acidentes de trânsito. Há que se considerar, ainda, que relaçôes precárias de trabalho influenciam diretamente o nível de saúde desses trabalhadores, como evidenciado por Bohle et al. (2004), em Sidney (Austrália), em estudo com empregados de hotéis, no qual se observou que os sem vínculo empregatício tendiam a apresentar longas jornadas de trabalho, combinadas com baixa previsibilidade e pouco controle sobre o processo laboral, o que lhes acarretava maior conflito trabalho-vida pessoal e problemas decorrentes desse conflito, como distúrbios do sono, cansaço, desestruturação dos regimes alimentar e de exercícios.

Observa-se claramente, no discurso dos motoboys, que o enorme contingente de desempregados contribui para uma maior exploração dos motoqueiros recémadmitidos. Estes se submetem a ritmos intensos e às condições precárias de trabalho que lhes são ofertadas, assumindo maiores riscos para permanecerem no emprego, conforme ilustra a fala seguinte:

O errado é que, quando a pessoa entra no serviço, ela quer mostrar serviço, [...] porque ela vai rápido, ele quer chegar mais rápido; então, a gente, que é mais velho de casa, não vai se arriscar tanto, então a gente diminui; ele não, ele já quer mostrar serviço e já sai acelerado (M3).

Essa submissão dos novatos acaba impondo, aos motoboys mais experientes, um ritmo de trabalho também mais acelerado. Para eles, o chefe faz constantes comparaçôes a fim de aumentar a produtividade: "O motoqueiro aceita isso, você entendeu?... E se ele não aceita, outro aceita, com certeza” (M9). Assim, o ritmo dos motoboys iniciantes na profissão torna-se uma ameaça à manutenção do próprio posto de quem está há anos neste tipo de trabalho, gerando, nos mais experientes, sentimentos ambivalentes, ora de indignação perante a submissão dos novatos, ora de compreensão ou de pena - "Às vezes o coitado está ali por uma necessidade, porque estava há tempo desempregado; [...] querendo ou não, ele quer manter o emprego dele" (M11).

O desemprego pode induzir, entre os que conseguem se manter na produção, tanto ao aumento do número de horas trabalhadas como à maior intensidade de trabalho, gerando maior risco de acidentes (WÜNSCH FILHO, 1999). Outros autores apontam, ainda, o caráter destrutivo do capitalismo nas condições objetivas e subjetivas de vida, levando a um determinado modo de viver e morrer 
(ABRAMIDES; CABRAL, 2003), evidentemente desfavorável à classe trabalhadora, em especial em um contexto de desemprego e baixa escolaridade.

\section{Condiçōes favoráveis e desfavoráveis}

As principais vantagens da profissão, segundo os motoboys, são: sensação de liberdade, oportunidade de conhecer novos lugares da cidade, fazer novas amizades e uma sensação de maior autonomia em relação à execução das tarefas. Além disso, a remuneração aparece como condição favorável ao exercício da profissão.

Entre as desvantagens, são apontadas: sol, chuva, desgaste físico e emocional, risco de assaltos e, principalmente, o trânsito. Os motoboys relatam também outras dificuldades enfrentadas no dia-a-dia, tais como picadas de marimbondo, mordidas de cães e colisões provocadas pela perseguição da moto pelos animais. A falta de apoio das empresas que os contratam e de garantias trabalhistas em caso de acidente ou doença também é apontada diversas vezes, permeando grande parte da discussão, como grande desvantagem do tipo de trabalho. Esta falta de apoio também se traduz no não-fornecimento de produtos como o protetor solar para a realização de entregas sob sol, e na falta de apoio financeiro à manutenção das motos. Os motoboys, neste contexto, comparam-se aos motociclistas dos Correios, os quais, na visão do grupo, têm condições de trabalho ideais, recebendo adicional de periculosidade, protetor solar, jaqueta e bota de cano longo, e equipamentos para a moto, como, por exemplo, o que impede contato do condutor com o cerol das linhas de papagaios de papel, entre outras vantagens.

Apesar da sensação de liberdade e autonomia, a precarização do trabalho dos motoboys ficou evidente na discussão do grupo focal. O fato de apenas um entre 11 ter registro do emprego na carteira de trabalho revela situação ainda mais precária do que a notada entre operários da construção civil em Salvador (BA), onde pouco mais de um terço desses trabalhadores referiu ter registro em carteira (SANTANA; OLIVEIRA, 2004). Esses autores concluem que há necessidade de revisão da política previdenciária brasileira, no sentido de proporcionar cobertura de benefícios também aos trabalhadores que não contribuem com o sistema.

\section{Carga de trabalho e comportamento no trânsito}

Segundo os participantes deste estudo, a característica principal e inerente à profissão de motoboy é a velocidade na realização de entregas. A pressão patronal e dos clientes 
por entregas rápidas é citada como a principal causa do comportamento de risco por eles adotado no trânsito, como revelam as seguintes falas: "O patrão fala: o cara me ligou e pediu para ontem! Então você sai na contramão" (M1) e “[...] o patrão não quer nem saber...” (M8).

Assim, os motoboys do presente estudo adotam algumas estratégias para reduzir o percurso e andar mais rápido: evitar ruas com semáforos e quebra-molas; passar na "beirinha" dos quebra-molas (mesmo reconhecendo o risco de quedas); andar na contramão; escolher vias públicas que apresentem sincronia dos semáforos; não ficar parado em sinais vermelhos; "costurar no trânsito". O desrespeito às leis de trânsito é justificado pela necessidade de realizar um maior número de entregas em menor espaço de tempo, aumentando assim a produtividade. Os comportamentos arriscados no trânsito não ocorrem apenas pelo fato de os motoboys ganharem por produtividade, mas também, e principalmente, pela grande pressão exercida pelas empresas para a realização de entregas em um curto espaço de tempo, muito aquém do tempo necessário para realizá-las em segurança.

Estudos realizados com motoboys atuantes em Minas Gerais (DINIZ; ASSUNÇÃO; LIMA, 2005b) e no Rio Grande do Sul (VERONESE, 2004) apontam a pressão exercida por clientes como fator determinante para a organização do trabalho imposta pelas empresas que os contratam, o que submete a categoria à elevada densidade de trabalho. As exigências de pontualidade, presteza e confiabilidade são o principal fator para adoção de comportamentos de risco no trânsito. Ainda segundo os autores, aliada à pressão por entregas rápidas, aparece a remuneração por produtividade como fator responsável pela adoção de práticas nem sempre seguras na entrega de mercadorias. Os motoboys entrevistados por Veronese (2004) revelaram que, em uma escala de valores, a segurança acaba ocupando posição secundária em relação ao cumprimento das demandas de trabalho e da remuneração por produtividade. Este aspecto da relação trabalhador-cliente também é salientado por Minayo-Gomes e Thedim-Costa (1997, p. 27), que referem que, no setor de serviços, "o componente de alta significância, definidor de suas atividades, é a relação que se estabelece entre os trabalhadores e os clientes/usuários/consumidores". Portanto, os comportamentos de risco adotados no trânsito são reconhecidos pela categoria como fruto da organização do trabalho e da pressão exercida para entregas rápidas, "e não como necessidade particular na busca de fortes emoçōes, como imagina o senso comum" (DINIZ; ASSUNÇÃO; LIMA, 2005a, p. 49). 
Os participantes do grupo focal referiram trabalhar diversos períodos do dia e alternar os turnos de trabalho, conduzindo ao progressivo desgaste físico e emocional. Janssen e Nachreiner (2004) observaram, em investigação realizada em Oldenburg, Alemanha, com funcionários de diferentes tipos de empresa e com usuários de internet, que a alta variabilidade das horas de trabalho, em especial se controlada pela empresa, tem efeitos prejudiciais sobre a saúde e o bem-estar psicossocial. Outro estudo detectou que a maioria $(79,8 \%)$ dos 348 trabalhadores de enfermagem pesquisados de um hospital universitário de São Paulo trabalhava em sistema de turnos alternados, com efeitos deletérios em sua saúde, como déficits no desempenho físico, distúrbios neuropsíquicos, cardiovasculares e gastrointestinais, além de prejuízos na vida social e familiar (COSTA; MORITA; MARTINEZ, 2000).

Neste estudo, alguns motoboys relataram jornadas de trabalho de até 15 horas sem interrupçôes e de terem dormido enquanto dirigiam a moto em diversas ocasiões, ocasionando acidentes, em geral por quedas ou colisões contra objetos fixos. Em estudo realizado por Veronese (2004), os motoboys atuantes em Porto Alegre referem o fator "cansaço", causado pela sobrecarga de trabalho, como provocador de acidentes por falhas humanas, pois, segundo eles, quando cansados, ocorre diminuição dos reflexos e da atenção exigida no trânsito. Outra investigação, em Minas Gerais (DINIZ, 2003), revela que os motoboys se submetem a longas jornadas de trabalho e realizam horas extras para compensar a baixa remuneração obtida, tendo sido relatadas, por muitos deles, jornadas de trabalho de 13 a 15 horas diárias. A sobrecarga e a alternância de turnos de trabalho são, portanto, características do cotidiano laboral desses trabalhadores, levando ao desgate físico e psicológico. Queiroz e Oliveira (2003) consideram que o estresse causado pelas más condições de trabalho contribui para a ocorrência de acidentes de trânsito e que os motoboys são vítimas desse estresse, pois, em seu exercício profissional, arriscam-se no trânsito para serem rápidos na entrega de mercadorias.

Para ser motoboy, na visão dos participantes do grupo focal, é necessário ter conhecimento sobre o trabalho: não é só ter a habilitação, pois quanto menor a experiência apresentada, maiores serão as dificuldades enfrentadas no trânsito e para se manter no cargo: "Você pega uma pessoa, vamos supor, que tirou habilitação ontem, que já não tem noção de moto, ele não pode sair na rua fazendo entrega, ele não agüenta" (M3). E ainda: "O primeiro trânsito que ele pegar no meio do caos, fim de ano, essas coisas, ele está 'ferrado'” (M9). 
Veronese (2004) relatou, em seu estudo, a percepção de motoboys atuantes em Porto Alegre acerca da importância da experiência profissional quanto à adoção de comportamentos de risco no trânsito. Segundo eles, a falta de experiência leva os iniciantes a adotarem altas velocidades e a desrespeitarem as regras de trânsito, na tentativa de compensar o desconhecimento dos endereços das entregas e de atender às demandas profissionais. Por outro lado, segundo esses motoboys, o excesso de experiência também pode ser prejudicial, pois, com o passar do tempo, estes podem desenvolver um modo "arriscado" de dirigir.

\section{Riscos e acidentes}

Todos os participantes do presente estudo relataram ter se envolvido em um ou mais acidentes de trânsito, tanto durante o trabalho quanto no lazer, sendo alguns de grande gravidade. Dos 11 motoboys, sete referiram ter sido vítimas de acidentes no ano anterior à realização do grupo focal, tendo a maioria deles se envolvido em mais de um acidente. Dois motoboys referiram ter se envolvido em acidentes graves nos dois últimos anos. Os motoboys descrevem os acidentes com detalhes e assumem a responsabilidade nos casos em que seu comportamento ou imprudência geraram o acidente. Todavia, destacam que o desrespeito dos demais motoristas às leis de trânsito aumenta os riscos para os motoqueiros. Segundo eles, em alguns casos, a imprudência apresentada pelos motoboys se deve ao comportamento de terceiros:

Muitas vezes a gente acaba sendo imprudente também, mas porque os outros forçam a gente; eu furei o sinal vermelho várias vezes porque vinha um carro atrás dando farol [sinal de luz] que não iria parar; aí eu tive que "vazar junto", porque eu olhei para o retrovisor, e se eu paro ele passa por cima de mim. (M4).

Muitos motoristas, na percepção dos motoboys, atrapalham seu serviço propositalmente, possivelmente por estes serem mais rápidos no trânsito: "Eles acham que a gente está, por adiantar o trânsito, abusando. Eles não vêem que a moto já é um veículo para melhorar o fluxo" (M11). Os motoboys do grupo estudado referiram uma certa agressividade dos motoristas, que se traduz, por exemplo, na forma de "fechadas": "Quando uma pessoa que está dirigindo um carro fecha o motoqueiro, ela tem que pensar que uma hora ou outra ela vai precisar desse motoqueiro para entregar uma medicação, um dinheiro rápido ou para fazer um transporte [...]" (M2). Os motoboys demonstram, por outro lado, sentimento de 
raiva pelo desrespeito dos outros motoristas: "Eu queria ser uma carreta agora para passar por cima deste carro" (M5).

Veronese e Oliveira (2006) relatam que, segundo a percepção de motoboys atuantes em Porto Alegre, a sociedade age de forma dicotômica em relação à categoria: ao mesmo tempo em que sua presença é vista como necessária nas grandes cidades, estes recebem críticas quanto ao seu comportamento no trânsito. Os motoboys, apesar de estarem cientes de sua importância, sentem-se socialmente discriminados.

Vários autores apontam o período noturno como de grande ocorrência de acidentes de trânsito (QUEIROZ; OLIVEIRA, 2003; BARROS et al., 2003; BASTOS; ANDRADE; SOARES, 2005). Em concordância com outros achados, a maioria dos acidentes em que se envolveram os motoboys deste estudo ocorreu à noite. Alguns motivos contribuem para esta situação: sobrecarga de trabalho e fadiga apresentada pelos motoboys, além do maior desrespeito às leis de trânsito que ocorre durante a noite. A fadiga é reconhecida pelos motoboys como grande causadora de acidentes, pois, como já exposto, vários referiram ter "cochilado" enquanto dirigiam a moto e dois, inclusive, relataram acidente por esta razão.

Segundo a percepção dos motoboys, seu serviço é arriscado, tanto para eles mesmos, quanto para outros usuários da via pública: "Motoqueiro, você sabe, é um risco total. Não adianta falar que anda devagar ou rápido; é um risco total" (M6). Os participantes do grupo mostraram-se conscientes dos perigos a que estão submetidos. Apontam que o transporte de determinadas cargas, como botijões de gás e de galóes de água, oferece maior risco, pelo peso dessas mercadorias: "Porque a gente que mexe com gás, essas coisas... Tem um ditado aí que a gente é um homem-bomba, homem-bomba, rapaz com um botijão atrás" (M10).

Apesar de a maioria dos motoboys ter sofrido acidentes, estes continuam exercendo a profissão por necessidade ou por falta de outras opções de trabalho. Tentam justificar os riscos assumidos no exercício profissional por meio da remuneração obtida, como ilustra a fala seguinte: "Motoboy é perigoso, mas dá um retorno até bom, porque o salário compensa...” (M7). A falta de opções de outros trabalhos igualmente rentáveis para o seu sustento e de suas famílias denota a limitada capacidade de escolha desses trabalhadores, situação que reforça o ponto de vista de Castiel (1996, p. 258): "muitas pessoas não elegem estilos para levar suas vidas. Não há opções disponíveis. Na verdade, nestas circunstâncias, o que há são estratégias de sobrevivência”. 
Um aspecto interessante abordado pelos motoboys é o perigo existente em certos locais da cidade nos quais há grande violência urbana: "a gente que está na rua sabe os pontos que são perigosos ou não" (M8). Estes demonstram ter conhecimento e voz ativa na decisão de entregar ou não em áreas desconhecidas pela empresa.

É bastante evidente no discurso dos motoboys o medo de assaltos, principalmente à noite. Eles temem, primeiramente, por sua integridade. Algumas transgressōes são apontadas como medida preventiva aos assaltos, como furar sinais vermelhos, pois, segundo os motoboys, em caso de total parada no semáforo não dá tempo de "arrancar": "à noite você está no semáforo e o cara vem e te aborda; é melhor você levar uma multa, do que o cara levar a moto" (M10). No entanto, os motoboys justificam que furar o sinal não significa simplesmente passar direto: "a questão de furar não é ver o sinal vermelho e passar direto, você reduz, olha e vai embora" (M2). Vários motoboys relatam ter perdido a moto, carga transportada e dinheiro durante assaltos à mão armada, além de terem sofrido várias tentativas de assalto.

Estudo realizado por Costa et al. (2003) sobre as condições de trabalho de motoristas de ônibus urbano revela que vários fatores são determinantes para a presença de estresse na categoria. A variável mais importante na determinação do estresse foi o medo de acidentes, o que aumenta a chance de estresse em $71 \%$ em relação aos motoristas que não têm essa preocupação. Já o medo de assaltos aumenta a chance de estresse em 65\%, e a extensão da jornada de trabalho em 54\%.

Frente às inúmeras dificuldades e perigos a que estão expostos os motoboys, são necessários mecanismos de defesa potentes para suprimir o medo e permitir a continuidade do exercício profissional. Talvez sua permanência na profissão, além da possibilidade de obtenção de renda, possa ser justificada pelos mecanismos de defesa desenvolvidos pela categoria ou, em outras palavras, segundo Dejours (1992), pela ideologia ocupacional defensiva. Se o medo não fosse neutralizado, os trabalhadores não poderiam desenvolver suas atividades por muito tempo. A consciência aguda do risco de acidente obrigaria o trabalhador a tomar tantas precauções individuais que ele se tornaria ineficaz do ponto de vista da produtividade. Observa-se que, apesar da gravidade dos acidentes mencionados na discussão, os relatos são sempre acompanhados por sátiras e brincadeiras, procurando-se, desta forma, reduzir a importância dos acidentes: "Eu conversei com São Jorge e São Pedro e pedi para voltar pra baixo logo" (M5). Também, ao serem indagados sobre o envolvimento em acidentes, os motoboys generalizam sua 
ocorrência para todo o grupo, como se fosse absolutamente comum à profissão, tentando-se com isso reduzir o medo, compartilhando o risco: "Eu acho que não tem quem não sofreu [acidente de trânsito]" (M6). Por outro lado, a visão do que é "acidente" para o grupo é bastante restrita, sendo a queda de moto (sem colisão) considerada parte do cotidiano desses trabalhadores: "Tombo você tem é direto... Eu nem sei se foi acidente...” (M7) [neste caso, houve freada brusca para evitar uma colisão, a moto se arrastou e o motoboy sofreu queda ao solo].

Durante a discussão foi levantada a seguinte questão: Quanto vale a vida? Será que compensa atender às exigências feitas, segundo eles, por patrôes e clientes injustos? Alguns motoboys preferem não se arriscar por exigências absurdas feitas por patrôes e empregadores, nem mesmo para aumentar seus rendimentos: "Eu vou correr o possível, porque eu não vou colocar minha vida em jogo por causa de R\$ 5,00 ou R\$ 10,00, não” (M11).

Devido aos inúmeros relatos de más condições de trabalho e exploração, surgiu durante a discussão o tema "sindicalização". Os motoboys mostraram-se indignados e sugeriram a criação de um sindicato dos motoboys para fazer frente à organização do trabalho vigente. Em estudo recente realizado em Belo Horizonte e em Uberlândia (MG), por Diniz, Assunção e Lima (2005b), os motoboys demonstram preocupação em relação à ocorrência de acidentes de trânsito e com suas condições de trabalho. Essa preocupação aparece no desenvolvimento de estratégias para atingir os objetivos de produção com segurança, como, por exemplo, no planejamento temporal, na elaboração de rotas que permitam maior agilidade nos serviços e nas negociações sociais visando a melhorias de suas condições de trabalho, com a elaboração de convenção coletiva do trabalho entre sindicato representante da classe e empresários do setor, permitindo que os motoboys prestem serviços de maneira eficiente, mas sem a necessidade de assumir altos riscos no trânsito. Em Londrina, a categoria ainda não é organizada, o que colabora para a manutenção das condições adversas de trabalho relatadas pelo grupo estudado.

\section{Considerações finais}

Os motoboys reconhecem sua imprudência no trânsito. Entretanto, relacionam essa imprudência às características inerentes ao trabalho. $\mathrm{O}$ risco de acidentes é reconhecido como conseqüência da organização do trabalho, e sua assunção é o último recurso da categoria frente à pressão dos clientes, à elevada demanda de 
serviços, às precárias relações de trabalho e ao grande número de fatores nãocontroláveis que se contrapóem ao seu exercício profissional, como o trânsito lento, condições climáticas, dentre outros (DINIZ, 2003). As condições precárias de trabalho foram evidenciadas, traduzindo-se na ausência de contratos formais de trabalho, negação de direitos trabalhistas, condiçôes adversas no cotidiano do serviço, jornadas extensas de trabalho e alternância de turnos, gerando estresse e cansaço físico, a ponto de os motoboys dormirem enquanto dirigiam.

A pressão vivenciada no trabalho assume diferentes formas e é um mecanismo poderoso tanto de influência deletéria na saúde física e mental do trabalhador como na potencialização do risco de acidentes de trabalho (SCHMIDT, 2006). Dentre as formas de pressão, a por produtividade, exercida por empregadores e clientes, é característica dominante do trabalho dos motoboys, fazendo com que esses trabalhadores se sintam constantemente preocupados com prazos e cumprimento de metas, o que os leva, freqüentemente, a conduzir a moto em desacordo com as regras de trânsito e a adotarem comportamentos que potencializam os riscos de acidente. A intensidade, o ritmo acelerado no trabalho e o número excessivo de horas na jornada são decisivos na deterioração da qualidade de vida e de saúde dos trabalhadores, podendo retirá-los precocemente do mercado de trabalho (ABRAMIDES; CABRAL, 2003).

Estes profissionais se tornaram, atualmente, indispensáveis aos grandes e médios centros urbanos, devido ao ritmo de vida acelerado e às demandas de nossa sociedade de consumo. Melhorar suas condições de trabalho e de vida é o grande desafio colocado no momento, tanto para os próprios motoboys, por meio da união da categoria e luta pelos seus direitos, como para a sociedade em geral. Ao Estado cabe urgentemente regulamentar e fiscalizar as empresas que oferecem serviços de entrega, assim como estabelecer normas que aumentem a segurança desses motociclistas no desempenho do seu trabalho.

\section{Agradecimentos}

Ao Departamento de Ciência e Tecnologia/Secretaria de Ciência, Tecnologia e Insumos Estratégicos/Ministério da Saúde e ao Conselho Nacional de Desenvolvimento Científico e Tecnológico (CNPq), pelo apoio financeiro (CTSaúde/CNPq 24/2004 - processo 505.875/2004-7). 


\section{Referências}

ABRAMIDES, M. B.; CABRAL, M. S. R. Regime de acumulação flexível e saúde do trabalhador. São Paulo Perspec. São Paulo, v. 17, n. 1, p. 3-10, 2003.

ALMEIDA FILHO, N.; COUTINHO, D. Causalidade, contingência, complexidade: o futuro do conceito de risco. Physis: Rev. Saúde Coletiva. Rio de Janeiro, v. 17, n. 1, p. 95-137, 2007.

ANDRADE, S. M.; MELLO JORGE, M. H. P. Características das vítimas por acidentes de transporte terrestre em município da Região Sul do Brasil. Rev. Saúde Pública. São Paulo, v. 34, n. 2, p. 149-156, 2000.

AYRES, J. R. C. M. Sobre o risco: para compreender a epidemiologia. São Paulo: Hucitec, 1997. $327 p$.

BARDIN, Laurence. Análise de conteúdo. Lisboa: Ediçōes 70, 1977. 113p.

BARROS, A. J. D. et al. Acidentes de trânsito com vítimas: sub-registro, caracterização e letalidade. Cad. Saúde Pública. Rio de Janeiro, v. 19, n. 4, p. 979-986, 2003.

BASTOS, Y. G. L.; ANDRADE, S. M.; SOARES, D. A. Características dos acidentes de trânsito e das vítimas atendidas em serviço pré-hospitalar em cidade do Sul do Brasil, 1997/2000. Cad. Saúde Pública. Rio de Janeiro, v. 21, n. 3, p. 815-822, 2005.

BOHLE, P. et al. Working hours, work-life conflict and health in precarious and "permanent" employment. Rev. Saúde Pública. São Paulo, v. 38, Supl., p. 19-25, 2004.

CARLINI-COTRIM, B. Potencialidades da técnica qualitativa grupo focal em investigações sobre abuso de substâncias. Rev. Saúde Pública. São Paulo, v. 30, n. 3, p. 285-93, 1996.

CASTIEL, L. D. Vivendo entre exposições e agravos: a teoria da relatividade do risco. Hist. Cienc. Saúde-Manguinhos, v. III, n. 2, p. 237-264, 1996.

CHAHAD, J. P.Z. Tendências recentes no mercado de trabalho: pesquisa de emprego e desemprego. São Paulo Perspec. São Paulo, v. 17, n. 3-4, p. 205-217, 2003.

COSTA, L. B. et al. Morbidade declarada e condições de trabalho: o caso dos motoristas de São Paulo e Belo Horizonte. São Paulo Perspec. São Paulo, v. 17, n. 2, p. 54-67, 2003.

COSTA, E. S.; MORITA, I.; MARTINEZ, M. A. R. Percepção dos efeitos do trabalho em turnos sobre a saúde e a vida social em funcionários da enfermagem em um hospital universitário do Estado de São Paulo. Cad. Saúde Pública. Rio de Janeiro, v. 16, n. 2, p. 553-555, 2000.

DEBUS, Mary. Manual para excelencia en la investigación mediante grupos focales. Washington: Porter Novelli, 1988.72 p.

DEJOURS, Christophe. A loucura do trabalho: estudo de psicologia do trabalho. 5. ed. ampliada. São Paulo: Cortez-Oboré, 1992. 168 p. 
DINIZ, Eugênio P. H. As condiçôes acidentogênicas e as estratégias de regulação dos motociclistas profissionais: entre as exigências de tempo e os constrangimentos do espaço. Dissertação (Mestrado em Engenharia de Produção) - Departamento de Engenharia de Produção, Universidade Federal de Minas Gerais, Belo Horizonte, 2003.

DINIZ, E. P. H.; ASSUNÇÃO, A.A.; LIMA, F. P. A. Por que os motociclistas profissionais se acidentam? Riscos de acidentes e estratégias de prevenção. Rev. Bras. Saúde Ocup. São Paulo, v. 30, n. 111, p. 41-50, 2005a.

- Prevenção de acidentes: o reconhecimento das estratégias operatórias dos motociclistas profissionais como base para a negociação de acordo coletivo. Ciênc. Saúde Coletiva. Rio de Janeiro, v. 10, n. 4, p. 905-916, 2005 b.

INSTITUTO DE PESQUISA ECONÔMICA APLICADA. Impactos sociais e econômicos dos acidentes de trânsito nas aglomeraçôes urbanas brasileiras: relatório executivo / Ipea, ANTP. Brasília, 2003. Disponível em: http://www.ipea.gov.br. Acesso em: 25 abr. 2004.

JANSSEN, D.; NACHREINER, F. Health and psychosocial effects of flexible working hours. Rev. Saúde Pública. São Paulo, v. 38, Supl., p. 11-18, 2004.

MINAYO-GOMES, C.; THEDIM-COSTA, S. M. F. A construção do campo da saúde do trabalhador: percurso e dilemas. Cad. Saúde Pública. Rio de Janeiro, v. 13, supl. 2, p. 21-32, 1997.

OLIVEIRA, P. A. B.; MENDES, J. M. Acidentes de trabalho: violência urbana e morte em Porto Alegre, Rio Grande do Sul, Brasil. Cad. Saúde Pública. Rio de Janeiro, v. 13, supl. 2, p. 73-83, 1997.

PAULILO, M. A. S.; JEOLÁS, L. S. Aids, drogas, riscos e significados: uma construção sociocultural. Ciênc. Saúde Coletiva. Rio de Janeiro, v. 10, n. 1, p. 175-184, 2005.

QUEIROZ, M. S.; OLIVEIRA, P. C. P. Acidentes de trânsito: uma análise a partir da perspectiva das vítimas em Campinas. Psicol. Soc. Porto Alegre, v. 15, n. 2, p. 101-123, 2003.

REIS, M. C.; CAMARGO, J. M. Desemprego dos jovens no Brasil: os efeitos da estabilização da inflação em um mercado com escassez de informação. Brasília: IPEA, 2005 (Texto para discussão no 1.116). Disponível em: <http://www.ipea.gov.br>. Acesso em: 10 mar. 2006.

SCHMIDT, M. L. G. Algumas reflexões sobre a influência de aspectos de organização do trabalho na gênese de um acidente de trabalho. Psicol. Am. Lat. [on line]. ago. 2006, n. 7. Disponível em: http://pepsic.bvs-psi.org.br/scielo.php?script=sci_arttext \&pid=S1870350X2006000300012\&lng=pt\&nrm=iso. Acesso em: 25 fev. 2008.

SILVA, N. E. K.; ALVARENGA, A. T.; AYRES, J. R. C. M. Aids e gravidez: os sentidos do risco e o desafio do cuidado. Rev. Saúde Pública. São Paulo, v. 40, n. 3, p. 474-481, 2006.

SPINK, M. J. Trópicos do discurso sobre risco: risco-aventura como metáfora na modernidade tardia. Cad. Saúde Pública. Rio de Janeiro, v. 17, n. 6, p. 1.277-1.311, 2001. 
SPINK, M. J.; MEDRADO, B.; MELLO, R. P. Perigo, probabilidade e oportunidade: a linguagem dos riscos na mídia. Psicol. Reflex. Crít. Porto Alegre, v. 15, n. 1, p. 151-164, 2002.

VERONESE, Andréa M. Moto-boys de Porto Alegre: convivendo com os riscos do acidente de trânsito. 2004. 138 p. Dissertação (Mestrado em Enfermagem) - Escola de Enfermagem, Universidade Federal do Rio Grande do Sul, 2004.

VERONESE, A. M.; OLIVEIRA, D. L. L. C.. Os riscos dos acidentes de trânsito na perspectiva dos moto-boys: subsídios para a promoção da saúde. Cad. Saúde Pública. Rio de Janeiro, v. 22, n. 12, p. 2717-2721, 2006.

WESTPHAL, M. F.; BÓGUS, C. M.; FARIA, M. M. Grupos focais: experiências precursoras em programas educativos em saúde no Brasil. Bol. Of. Sanit. Panam. Washington, DC-USA, v. 120, n. 6, p. 472-481, 1996.

WORLD HEALTH ORGANIZATION. World report on road traffic injury prevention. Geneva: WHO, 2004. Disponível em: http://www.who.int/violence_injury_prevention/publications/ road_traffic/world_report/en/index.html. Acesso em: 7 abr. 2004.

WÜNSCH FILHO, V. Reestruturação produtiva e acidentes de trabalho no Brasil: estrutura e tendências. Cad. Saúde Pública. Rio de Janeiro, v. 15, n. 1, p. 41-51, 1999. 


\section{Work Conditions and Risks in the Urban Traffic from the viewpoint of Motorcyclist Workers} In Brazil, the professional motorcyclist is one of the professions that most increase, what may contribute to their higher involvement in traffic accidents. This study aims to identify and analyze, in a qualitative perspective, the perceptions motorcycle delivery boys have about their work, traffic risks and occurrence of accidents. Data was collected in a focus group conducted in February 2005, with 11 motorcycle delivery boys who worked in Londrina, State of Parana, Brazil. This article focuses on the main reasons for motorcycle delivery boys to be engaged in the occupation, their work conditions, the risks they are exposed to and their involvement in accidents. The main reasons for undertaking this job were unemployment and low educational level. Pressure exerted by companies and customers for fast deliveries is a decisive factor for the adoption of risky behavior in traffic, having the earnings by productivity less importance in the decision-making process. All participants of the study reported involvement in traffic accidents. To improve their work conditions is the great challenge of the moment, as much for these workers, through their union and the fight for their rights, as for the general society. It is the State's responsibility to regulate and supervise the companies that offer their services and to establish rules that increase motorcyclists' safety in their work performance.

> Key words: Accidents; traffic; motorcycles; working conditions; risk-taking; occupational risks. 